\title{
Elementary Supplementation: Analyzing Missing and Dislocated Media Literacy
}

\author{
Dongni Liao ${ }^{1}$ \\ School of Journalism and Communication \\ Central China Normal University \\ Wuhan, China
}

\author{
Zuosu Jiang ${ }^{2}$ \\ School of Journalism and Communication \\ Central China Normal University \\ Wuhan, China
}

\begin{abstract}
As a basic literacy, media literacy surpasses and integrates the three parts of moral accomplishment, scientific literacy and literature and history literacy. Its cultivation should combine school, family, government, society, media and school education as the core. The elementary supplementation can be effective only if all parties actively participate and work together; only if we know all kinds of performance of literacy dislocation we can effectively prevent and control the dislocation of media literacy.
\end{abstract}

Keywords-communication field; literacy; media literacy; media dependency

\section{INTRODUCTION}

In civic literacy, the general missing of media literacy is a universal phenomenon. After increasingly frequent propagation behavior and the acceptance of propagation behavior, and it turning into the most common behavior of humans, the importance of media literacy has become more obvious. Media literacy has become one of the most important qualities that every modern person should have. Therefore, the media literacy education has developed into a worldwide social movement.

\section{MEDIA LITERACY HAS BECOME AN IMPORTANT FACTOR OF THE EDUCATIONAL ENVIRONMENT}

Contemporary society is a society with limited resources of competitive allocation. Information resources have become important resources for personal development and they are also crucial resources for the existence and development of community and society. As one of the main channels of information spreading, the mass media infuses the media's point of view in the process of information spreading. The construction of it using subjective colors inevitably makes the information gained by readers and listeners have a certain tendency towards an opinion.

The citizens in our information society can be regarded as many "information cells". Every citizen should know media, understand media, analyze media and use media. Media literacy not only is regarded as the strength of the public side to check and balance the unhealthy performance of media, and embodies the constituent parts of rights and responsibilities, but also strengthens the communication rights of the public and the responsibilities of the public for the positive effects played by mass media in democratic mechanisms. [1] What's more, the status of citizens' media literacy has become a kind of basic survival skill. There are two big differences between it and the professional education of news media: the first is that the object of media literacy are all citizens; the second is that the main content of media literacy uses people's cognitive abilities for all kinds of media, and the resolving ability for the contents of media. It has obvious characteristics of practicality.

Since entering the new century, mobile communication and internet are using their great radiation to affect the development of human society. Because of the advanced position of network development in Chinese society, institutions of higher learning have become important places for all kinds of cultures and thoughts to interact and collide. From the communication perspective, the campus environment has become a typical communication field of the saturation type. Activities of transmission which use new media as medium have permeated into all levels on campus. Analyzing its relative importance, media influence is not the alternative factor any longer. Media and class have become teaching fields of equal importance. At present, not only the internet has millions of websites to provide a wide range of information services, but also the "MOOC" online classes led by Harvard and Massachusetts Institute of Technology have provided more than 3,000 high quality lessons for sharing without borders. Media, on one hand, makes the effect of family education become weaker. On the other hand, it gradually breaks up the traditional core status of school education and redistricts the sphere of influence of many big education territories. The increasing relative importance of media on campus is also a symbol of a situational transformation of statistical significance and belongs to the prior category of elements to enter the decision matrix.

From the perspective of the scope of the world, media literacy education has become an important part of basic cultivation. The idea of media literacy education was first proposed by educators of various countries in Scandinavia in the 1930s. [2] In America, where the development of the network happend earlier, the media literacy education is 
defined from a practical perspective as 'Students' selective ability, comprehensive ability, questioning ability, evaluating ability, creative ability and manufacturing ability as well as critical thinking and reaction ability when they meet all kinds of information about media." [3] Through accepting media literacy education, college students can better grasp the knowledge and skills to use media and pay attention to the function of media with maximum efficiency, and they can better realize their dreams and serve society. Meanwhile, they can effectively avoid being perceived by media and becoming its slaves.

According to a campus survey in the Hubei area, not differentiating between science or liberal arts students, and not paying attention to the relative importance of preferences or instrumental use, under the condition of the average probability of internet usage, four out of five students think that the influence that the internet has on them on campus is more than teachers have on them. In other words, the internet has the most important effect on students' cultivation. Media literacy education is not only required in our current society, but also required and crucial at any time in the future, which is not different from formative education and knowledge education.

Contemporary college students have become the information "client" of holographic load. No matter selecting courses or making friends, getting information or participating in the activities, from entering the school to leaving school, every step of students cannot be divorced from the shadow of media. It can be asserted that if students break away from media, it is impossible for them to learn effectively or even live a normal life. In the meantime, media communication activities outside the campus have profound influences on students. Media has become one of the more and more important elements in the campus environment and the whole social environment. Facing this situation, if media literacy education is being ignored, it will not only delay the development of student but even affect the progress of the whole society. From the communication perspective, it also means missing out in the communication field. Therefore, schools must effectively carry out media literacy education, and fill the elementary blank of literacy education. Only in this way can they better adjust to the trend of internet updates at full speed.

\section{MEDIA LiteraCY BECOMES A BASIC LiteraCY FACTOR}

The increasing popularity of the internet makes educators gradually realize that media literacy has become the next generation's basic literacy. It is extremely urgent to let media literacy become a general course in the curriculum design in order to increase cultivation intensity. Education has close relationships with literacy. "Education" can improve humans' cultural level and explore human potency of all aspects; "literacy" is cultivation. Its effect is to develop thinking and behavior into life long habits and influence the value orientation of life. Education is a means, while cultivation is the purpose.
A research on the top 10 institutions of communication and journalism in America shows that the student scale remains stable and professional education in the media field is full of vigor without signs of decline. In the aspect of degrees structure, the degree types in the field of journalism and communication in America are abundant and they provide diversified dual degree programs, in which the settings of a dual degree combined with the science of law is the most common; in the aspect of a major setup, a small part of colleges tend to integrate specialties, and most of them tend to subdivide specialties, and the mode of personal customization has risen; in the aspect of curriculum provision, many colleges advocate liberal education, and the courses have characteristics of meticulous divisions and strong independent selectivity of students; in the aspect of teachers, there is a high proportion of high-grade teachers in colleges. Many colleges and universities pay attention to teachers' professional practice to cultivate students' practical operation skill; American journalism and communication education is rooted in the education before the university entrance as well as integrates into many sides of college education. In England, media literacy education has become a part of the formal education system in the 1970s. In the late 1980s, England and Wales brought media literacy education into the curriculum of primary and secondary school, and combined media literacy education with existing disciplines through the forms of various topics and developed students' media capacity.

Journalism and communication through one hundred years have made an effort to make eastern and western scholars have some consensus in terms of literacy, for example, all people admit some facts: all media information is built and the purpose of media information is to gain profit; media integrates values and opinions and different people have a different understanding of media. In this way, humans should have early and clear education for their media culture. Shinichi Suzuki, one of Japan's early education experts, thinks, "Education should start from 0 years old". [4] This opinion has enlightening meaning on the "early grasp" and "grasp from early time" in the aspect of media literacy. "Early grasp" means initiative; "grasp from early time" can obtain earlier benefits and avoid being difficult to turn round after making detours. America does great on two aspects of "early grasp" and "grasp from early time", and since the 1960 s, citizens in primary and secondary schools have begun to accept systematic media literacy education, which achieves significant results.

Basic literacy mainly refers to three major accomplishments of morality, science, literature and history. The reason why we say media literacy has become a basic literacy factor is that media literacy not only overlaps with the above three major accomplishments and can put them together as a whole, but also can promote the development of the three main accomplishments respectively. As a leading literacy, if being developed or strengthened through college education, media literacy will be able to consolidate knowledge, broaden the mind and activate the innovation, form a perfect personality and then lay a profound foundation of humanistic ethics. Wuhan is a city with many 
colleges and universities, the research on college students in Wuhan shows that one of the differences between outstanding students and students with poor performance is that whether they have good media literacy, and it is also a very important difference. Outstanding students won't be affected by the negative influence of the internet, and they can make use of the network. They use the internet to improve learning efficiency, enhance social communication and the IQ and EQ develop simultaneously. However, the students with poor performance are the opposite. They don't have strong self control and clear cognition when facing the internet. On the contrary, they are controlled by the internet, which is not only a problem for students but also a dead zone of education. It should cause the educators' vigilance. "When the speed of mass media popularization surpasses the speed of mass media literacy, the negative effect of media will be more obvious, at least the condition that staggers and contends against the positive effect". [5]

\section{MEdia Literacy EdUCATION Plays A DECISIVE ROLE IN MANAGEMENT}

The cultivation of media literacy of the public plays a vital role in the sound development of society. To achieve sound development, we need to combine all the driving forces. The media literacy education carried out by educational and administrative development has become a universal and vital literacy course for the public. James Heerlen stressed that media literacy education could not fully play its role without the cooperation of people of all kinds in China. [6]American Bengali Selman Khan who is respected by Bill Gates has established the Khan Academy. At the beginning, he taught math online to kids who were his relatives. Then he started to teach other subjects. Since you can have access to the internet, you can listen to his class online. The Khan Academy is developing more and more. The most important reason for its sound development is that Khan is equipped with great media literacy. Meanwhile, he can deal with media details that others are not able to find out. For example, he does not appear in the teaching videos, which are compact as well. There is only a tablet on which there are math formulas and figures. We can listen to his explanation, too. He thinks that the traditional teaching video makes teachers superior to their students because of their endless explanation in front of the blackboard. Just as Steve Jobs put it, every node of Internet contains culture and literacy. Media literacy education is a systematic project which is an organic unity. To make advanced development, schools, family, media, society and students should cooperate well.

Since the 1990s, we have begun to study and promote media literacy education in mainland based on the translation and research of western countries. In this case, it is nearly 50 years later than in western countries. So it is at the starting point now. In order to raise the media literacy of the whole society and enhance the soft power of China, media literacy education should achieve a leap in its development. John Pungent, who is acknowledged as the "Father of Media Literacy Education" in Canada, has given 9 factors that are substantial for media literacy education. At the same time, he has attached great importance to the overall combination of people of all kinds. For example, as the first one stressed, media literacy education is an activity of gross-root people, also called a "Gross-root Activity". Teachers need to pave the way for this activity. The second one is that educational administrators are supposed to support it; colleges and universities should provide course installation and advisors for it. Then, there is the seventh, "In order to promote the course and make people have access to newsletters, professional assistant agencies should be established timely not only in schools, but also in those departments that have interest in media literacy". [7]

Among these factors, Pungent has attached great importance to the establishment of "assistant agencies". Those agencies are mainly social organizations and industry associations. They have fully played their role in the practice of media literacy education in modern western countries. For example, the non-profit organization 'Centre for Media Literacy', which was found in 1989, provided a core concept and vital goal for media literacy development in America. It became the main framework for implementing media literacy education all over America. [8]Australia is known for its well-developed media literacy education. A national teachers" organization called "Australia Teachers Media" holds a national conference every 18 months for the discussion of questions about media literacy education. It has become a famous summit of this field. [9]

Based on the research of the condition of media literacy education in many countries, Pungent concluded that "As there are various skills and professional knowledge included, the cooperation of teachers, students, government, researchers, social associations and media exports is of great significance". [10]

\section{Dislocation Has Made It DifFicult For Media LITERACY CULTIVATION}

College students are in the critical period of transition from natural personas to social personas. They have special demands in study, lives and emotion. Using media has become common in their daily lives. However, as the group that most favors Internet, the college students have suffered media literacy dislocation to a large extent.

Commercialization and amusement of media makes the students have wrong recognitions and actions in regards to media. The following six can reflect media literacy dislocation. They are media dependency, media abuse, media paranoia, media incapability, media nihility and the media gap.

When McLuhan advanced that "Medium is the message", he changed a letter of a word so it became "Medium is the massage". So there are two theories that inspire people. Massages can make people feel relaxed and happy, but when they last long, people may rely on it. To some extent, the effect of media information is similar with that of a massage. The media dependency theory was developed by the famous American scholars Melven L. Defleur and Sandra BallRockeach. This theory points out that when a new medium becomes familiar to people, people will dependent on it more, 
even though medium and people both need each other. When a man is satisfied with a medium, he will expect to get more information from it and rely on it more. [11] "The furthest distance in the world is that we are together but you are focusing on your cell phone." The first thing when one wakes up in the morning is to hold his or her mobile phone in their hand, as it is the last thing before going to sleep. College students can benefit from media, while if they rely on the media too much, they may miss the opportunity to raise their own ability.

Media abuse means random and addictive usage of media, especially mass media, which is a power and can play a vital role in society. However, some media users have low media literacy; they randomly use media. For example, cyber manhunts and network onlookers have cause negative effects in society. The internet platform has many features. For example, netizens are large in number, unsystematic, they rely on each other. As college students are changing their way of communicating with others, discussed issues are becoming more and more; students favor "edgier" personalities and the abuse of network actions. The medium can enlarge the effect brought about by individuals or a group of people. If it is over used, it will infringe on other people's right, such as the right of portrait and the right of privacy. It will bring chaos which has already existed online to the real world.

Paranoia is a term from psychiatry. It means that a man insists on his own paranoid opinion. If other people do not agree with his opinion, he will be hostile to them. At present, most students suffer from "repost paranoid". They can't think calmly, and they may easily neglect the value of things. Dominated by shallow moods, they even become machines to copy information. They are wasting their right of expression.

Media incapability, as the name suggests, means the incapability in media usage, information consumption, information production and social interaction. When using traditional media, people do not need to have special abilities, except for paper media which requires reading ability of users. However, things become different with the new media. Terminals like computers, mobile phones and tablet PCs all require users with relative operation skills. Some students from areas where the education and information infrastructures are backwards have no basic ability to use these terminals. In the media era, information expansion is becoming fiercer, the origin is diversified. Thus, the dewyeyed students are facing a complex environment of picking out information. In this way, they should be trained to have the ability to judge and pick out the right information. [12]

Media nihility is originated from Taoism. Nihilism suggests that there is no point in the existence of the world, and especially human beings, let alone the truth and initial value of things. Media nihilists blindly deny and reject the function of media in society. They think media is intangible. What's worse is that the advancement of media technology does not keep up with social development. As a result, there is a media gap. The gap between media and technology can affect students' recognition. From the vertical axis of time, the research and practice of media literacy education still have a long way to go. We need to start from the little things and make endless efforts, instead of relying on words, a few courses and social activities.

From the horizontal axis of time, the system of media literacy education includes family, school, community education, national legislation, policy and so on. Only by the integration of these five can we promote high quality of media literacy. In the USA, to raise the quality of media literacy of teachers, various media literacy education activities have been carried out. In some of the states, media literacy is combined with English and other subjects to be taught in class by teachers. In other states it is taught as a single subject. In society, there are many important media literacy organization such as "TV consciousness training".

The developing model of media literacy education that contains the integration of family, school, government, society and the medium has been formed in many countries, such as the United States, Canada and the United Kingdom. It can help promote the development of media literacy education. Their developing model is making school education its central mean; family their assistance; government departments and social organization a driving force; all kinds of media their "polisher". It has been found that the developing experience can serve as a reference. Therefore, based on the condition of the Chinese media literacy education and its own characteristics, we need to learn from their experience with a critical mind.

\section{REFERENCES}

[1] Lu Ye. Global Vision and Chinese Context of Media Literacy[J]. Today's Mass Media, 2008(2)

[2] Yuan Jun. Global Vision and Chinese Model of Media Literacy Education[J]. Journal of International Communication, 2010(5)

[3] Zhou Zhiping. Analysis on the Situation and Countermeasures of Chinese Media Literacy Education[J]. Chinese Editors Journal, 2009(5)

[4] Shinichi Suzuki. 21st Century 0 Year-old Education Scheme[M] Beijing: China Light Industry Press,2001

[5] Tian Weiyi. Media Literacy Education for College Students[J] Modern Communication, 2004(6)

[6] Long Lifei. On the Content, Principal and Way of Media Literacy Education[J]. Journal of Guangdong Ocean University, 2008(4)

[7] [Canada] John Pungente, Yu Yazhuo. The Second Wave: Media Literacy Education in Canadian High School[J]. Media Studies, 2004(02)

[8] Zhang Yi, Zhang Zhian. The Characteristics and Experience of Media Literacy Education in the US[J]. Journalism Review, 2007(10)

[9] Li Xianfeng. The Education and Inspirations of Media Literacy in Australia[J]. Journal of Educational Studies, 2012(6)

[10] [Canada] John Pungente, Yu Yazhuo. The Second Wave: Media Literacy Education in Canadian High School[J]. Media Studies, 2004(02)

[11] Shan Xiaohong. Introduction of Media Literacy[M]. ZheJiang: Zhejiang University Press, 2008

[12] Peng Lan. Three Kind of Media Literacy and Their Relationship in Socialized Media Era[J]. Journal of Shanghai Normal University, 2013(3)

[13] Hu Lianli, Wang Jiaqi. The Progress and Missing of Media Literacy Education in Mainland [J] Journal of Hebei University, 2007(1) 